\title{
A qui appartient votre hôpital?
}

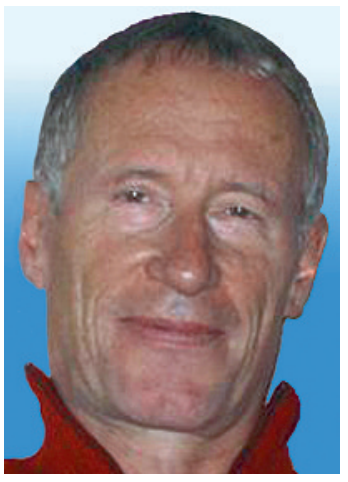

Erhard Taverna
Le dossier du «Zeit-Magazin» du 12 mars 2009 a révélé des choses étonnantes: pendant de nombreuses années, des communes allemandes ont bradé des biens publics tels que tramways, réseaux électriques, stations d'épuration des eaux usées, hôpitaux et écoles, par l'intermédiaire d'investisseurs américains. Vu de plus près, ce bradage a eu lieu dans le cadre d'un modèle d'épargne fiscale, nommé Cross-Border-Leasing (CBL). On a commencé tout d'abord à vendre à des trusts américains, par le biais de différentes banques, des réseaux d'égouts et des usines d'incinération des déchets puis des halles de foire, des tunnels, des gares et des lignes à haute tension, finalement des hôpitaux et même un hôtel de ville. Une fois vendus, ces biens ont immédiatement été loués aux propriétaires initiaux dans le cadre d'un contrat de longue durée, et la ville a obtenu sans délai une partie des impôts épargnés aux Etats-Unis à titre d' ' «avantage en valeurs réelles», la plupart du temps 2 à $8 \%$ du volume total des transactions.

Les premières années, de nombreuses communes européennes ont pu assainir leurs comptes grâce à ce modèle CBL. En Suisse également, des cantons et des villes ont cédé une partie de leurs droits de propriété généralement à des partenaires contractuels anonymes établis aux Etats-Unis, par exemple la compagnie des trains rhétiques des Grisons ou le réseau des transports publics de la ville de Zurich à la Bank of New York. Selon un article paru en 2004 dans la «Wochenzeitung», Skyguide, qui est en charge de la sécurité aérienne suisse, aurait, en 2001 et 2002, également placé plusieurs centaines de millions de francs sur 15 ans chez un investisseur américain.

Le terme d'investisseur est toutefois trompeur car rien n'est investi. Il s'agit d'une combine fiscale qui permet aux grandes entreprises de réaliser, par des transferts fictifs de titres de propriété, d'énormes amortissements de technique fiscale à la charge du contribuable. En 2005 déjà, lorsque les hypothèques «subprimes» étaient encore des machines à sous intactes, l'administration financière américaine estima que ces transactions de leasing étaient des manœuvres abusives pour échapper aux impôts et elle réduisit à néant leur avantage fiscal. Jusqu'à ce jour, ces contrats sont tous conclus à New York, car cet Etat fédéral les reconnaît même lorsqu'ils transgressent le droit en vigueur aux Etats-Unis.

Les conseillers communaux de tous bords politiques ont cédé à la tentation de l'argent ra- pide. Parlant très mal l'anglais, ils ont approuvé, par l'intermédiaire de banques et d'avocats, des textes contractuels compliqués comptant souvent des milliers de pages, et cédé des infrastructures publiques pour une durée allant parfois jusqu'à cent ans. Sans que son affectation soit modifiée, la fortune sise dans des placements a été transformée en capital de roulement ou actifs circulaires au bénéfice d'avantages fiscaux. Le risque incombe toutefois aux villes qui doivent veiller à ce que ses placements restent intacts. Toutes les réserves prévues dans ces contrats doivent être respectées, les placements ne peuvent être ni réduits ni dévalués même en cas de diminution de la rentabilité. Les villes doivent payer à prix fort le rachat des placements et lorsqu'elles veulent rénover une canalisation d'eaux usées ou restructurer certains hôpitaux, elles doivent en demander la permission à des avocats établis à New York.

Les gains sont constitués en grande partie de taxes, d'honoraires, de salaires et de provisions qui vont dans les poches des intermédiaires, avocats, banques hypothécaires, instituts financiers, agences de rating, assurances et administration. Les investisseurs, la plupart des firmes, mais aussi des personnes privées, se retranchent derrière des adresses inatteignables dans des paradis fiscaux américains tels que le Delaware ou le Connecticut. Ce qui a été salué un jour en tant que rétribution sans contrepartie s'avère être, en des temps d'endettement horrifiant, un mirage qui coûte cher, car tous les Etats bouchent leurs trous fiscaux avec la dernière énergie. Lors d'agissements contraires aux contrats, les communes sont tenues de réparer le préjudice causé, sans compter les coûts subséquents éventuels.

Aujourd'hui, les CBL sont considérés comme des affaires fictives sans contenu économique et avec des questions de droit pénal encore à éclaircir et donc un instrument financier supplémentaire qui s'est révélé être une bulle spéculative terriblement opaque et anti-démocratique. Entretemps, l'argent vient à manquer pour de nombreux hôpitaux publics. Si des crédits ne peuvent plus être obtenus, les contrats de leasing restent attrayants. Le 6 e symposium européen de la gestion hospitalière tenu à Vienne en début mars 2009 constate ceci: «Considering all this with thought, the lease contract should in each case be put to the acid test before closed.»

Erhard Taverna 